\title{
Digestive proteolytic activity in the gut and salivary glands of the predatory bug Podisus maculiventris (Heteroptera: Pentatomidae); effect of proteinase inhibitors
}

\author{
Howard A. BELL ${ }^{1}$, RACHel E. DOWN ${ }^{1}$, John P. EDWARDS ${ }^{1}$, JoHn A. GATEHOUSE ${ }^{2}$ \\ and Angharad M.R. GATEHOUSE ${ }^{3}$ \\ ${ }^{1}$ Central Science Laboratory, Sand Hutton, York, YO41 1LZ, UK \\ ${ }^{2}$ Department of Biological Sciences, University of Durham, Science Laboratories, South Road, Durham, DH1 3LE, UK \\ ${ }^{3}$ Institute for Research of the Environment and Sustainability, School of Biology, Devonshire Building, University of Newcastle, \\ Newcastle upon Tyne, NE1 7RU, UK
}

\begin{abstract}
Keywords. Digestive proteinases, proteinase inhibitors, Podisus maculiventris, Pentatomidae, Heteroptera, transgenic crops, salivary glands

Abstract. Proteinase activity in the midgut of the pentatomid stinkbug Podisus maculiventris was investigated. The optimal $\mathrm{pH}$ for adult and nymph proteolysis was $\mathrm{pH} 6.0$ and $\mathrm{pH}$ 6.5, respectively. Proteinase activity was characterised using a range of diagnostic inhibitors. Activity of both adult and nymphal gut extracts, detected by the hydrolysis of Z-Phe-Arg- $p$ NA, was inhibited to $<20 \%$ of control levels by several inhibitors (e.g. E-64 and chicken egg white cystatin) associated with the inhibition of cysteine proteinases. The less specific inhibitor leupeptin reduced proteolytic activity to around $1.0 \%$ of the control values. In-gel analysis of the enzymes revealed that proteolytic activity was due to at least four proteinases, of ca. 30, 36, 50 and $110 \mathrm{kDa}$, which were all susceptible to E-64 inhibition. Salivary gland extracts gave maximal activity at $\mathrm{pH} 8.0$ when tested for general proteolytic activity using fluorescent BODIPY-FL casein substrate, and showed moderate levels of inhibition when incubated with inhibitors of serine-, cysteine-, aspartic- and metallo-proteinases. Leupeptin and PMSF gave the highest levels of inhibition of salivary proteolytic activity, at ca. $50 \%$, whilst the plant-derived inhibitors SKTI, CpTI and OC-1 did not inhibit proteolysis.
\end{abstract}

\section{INTRODUCTION}

Proteinase inhibitors (PIs) occur frequently within the tissues of most plant families (Ryan, 1990) and have been ascribed several putative functions including that of conferring protection against phytophagous insect attack. Through specifically binding to proteolytic enzymes within the gut, forming highly stable complexes, they interfere with the digestive enzymes of pest insects causing reduced growth, increased levels of pest mortality and reduced plant damage (Laskowski \& Kato, 1980; Ryan, 1990).

In recent years, a large quantity of research has concentrated on producing genetically modified crops expressing genes encoding plant PIs for resistance to pest insects $(\mathrm{Xu}$ et al., 1996; Jongsma \& Bolter, 1997; Sane et al., 1997; Jouanin et al., 1998; Gatehouse \& Gatehouse, 1999). To date, a number of PIs have been demonstrated to have potential for pest control when expressed in transgenic plants. For example, the serine proteinase inhibitor cowpea trypsin inhibitor (CpTI) has been shown to have a detrimental effect against lepidopteran and coleopteran pests when expressed in transgenic plants (Hilder et al., 1987; Graham et al., 1995; Gatehouse et al., 1997; Bell et al., 2001). Similarly, soybean Kunitz trypsin inhibitor (SKTI) has also been shown to be effective against a range of pests (Johnston et al., 1993; Gatehouse et al., 1999). Oryzacystatin (OC-1), an inhibitor of cysteine proteinases derived from rice, has similarly been demonstrated to have insecticidal effects against aphids (Rahbe et al., 2003), coleopteran insects (Leple et al., 1995) and nematodes (Burrow et al., 1998; Cowgill et al., 2002) when expressed in crop plants, including potato and oilseed rape. Proteinase inhibitors expressed in transgenic plants, however, have the potential to adversely affect beneficial insects that feed on the target pest. This may be of particular importance when the expressed PI is targeted at a pest insect that is fed on by an insect predator that also utilises the same mechanistic class of digestive proteinases. The potential for PIs to have negative preymediated effects at the third trophic level has been the subject of several recent studies and some adverse effects of PIs on predators and parasitoids have been recorded (Ashouri et al., 1998; Bell et al., 2001). However, other studies have found few, if any, negative effects (PicardNizou et al., 1997; Bouchard et al., 2003a,b; Ferry et al., 2003).

Recently, Bell et al. (2004) investigated the effects of exposure of the predatory stinkbug Podisus maculiventris (Say) to the serine proteinase inhibitor CpTI using Lacanobia oleracea prey that had ingested transgenic potato leaves or had been injected with the inhibitor, and reported some detrimental effects. However, no attempt was made to equate the recorded effects with any impact on the digestive processes of the beneficial insect. Of the predatory Heteroptera, $P$. maculiventris is one of the most widely investigated and is currently used as a biological control agent in North America and Europe, primarily for the control of lepidopteran and coleopteran pests (De 
Clercq, 2000). Although, the proteolytic processes of $P$. maculiventris have received some attention previously (Stamopoulos et al., 1993; Cohen, 1995), there is little information available on the potential impact of PIs within the diet of this predator on either gut or salivary proteolytic activity. The effects of PIs in the diets of other predatory insect species have, however, been more fully elucidated. For example, Bouchard et al. (2003a,b) showed that OC-1 had little prey-mediated impact on the developmental parameters of a predatory heteropteran, Perillus bioculatus (F.), when investigated in a tritrophic system using transgenic potato expressing the PI, despite the fact that the inhibitor markedly suppressed in vitro gut proteolysis of the predatory bug. Similar findings were reported by Ferry et al. (2003) for the predatory ladybird Harmonia axyridis (Pallas) on exposure to OC-1 via its prey, and by Burgess et al. (2002) in the carabid Nebria brevicollis (F.) exposed to the serine PI aprotinin in a tritrophic (transgenic plant / prey / predator) system. Studies, such as those detailed above, serve to indicate that whilst the proteolytic activity of beneficial insects can be highly susceptible to inhibition by the PIs expressed in transgenic plants, it does not necessarily follow that measurable effects on a given predator's biology, or efficiency as a biological control agent, will ultimately result.

The aim of the present study was to characterise the digestive and salivary proteinases of $P$. maculiventris, through the use of diagnostic inhibitors. A major tenet of sustainable agriculture is to ensure the compatibility of pest control measures with beneficial predator and parasitoid species in order to generate enhanced control. The information gained here will allow us to predict whether detrimental effects are likely to occur when this economically important beneficial insect feeds on pests that have ingested plant material that has been modified to express proteinase inhibitors for insect resistance.

\section{MATERIAL AND METHODS}

\section{Reagents}

The substrate benzoyloxycarbonyl-L-phenylalanyl-L-arginine - $p$-nitroanilide (Z-Phe-Arg- $p$ NA) was obtained from Bachem (Saffron Walden, UK). Benzoyl-L-arginine- $p$-nitroanilide (BA $p$ NA), succinyl-L-alanine-L-alanine-L-proline-L-phenylalanine- $p$-nitroanilide (SAAPF $p$ NA) and azocasein were obtained from Sigma (Poole, UK). The inhibitors phenylmethanesulfonyl fluoride (PMSF), SKTI, L-1-chloro-3- [4-tosylamido]-4-phenyl2-butanone (TPCK), L-1-chloro-3-[4- tosylamido]-7-amino-2heptanone (TLCK), soybean Bowman-Birk trypsin-chymotrypsin inhibitor (SBBI), chymostatin, trans-epoxy succinyl-leucylamido-(4-guandino) butane (E-64), chicken eggwhite cystatin (CEW cystatin) and leupeptin were obtained from Sigma Co. Ltd (Poole, UK). The inhibitor CpTI was purified from mature cowpea seeds by affinity chromatography as described by Gatehouse et al. (1980), whilst OC-1 was purified from rice seeds according to Edmonds at al. (1996). All inhibitor stocks were prepared according to the supplier's instructions or as recommended by Beynon \& Bond (2001) and were used within their diagnostic concentration range. Bradford protein reagent was supplied by Bio-Rad Laboratories (Hemel Hempstead, UK). All other chemicals were supplied by Sigma.

\section{Preparation of $\boldsymbol{P}$. maculiventris gut and salivary gland} extracts

Adult $P$. maculiventris were obtained from a standard laboratory culture originally derived from insects purchased from Koppert (Wadhurst, East Sussex, UK) and maintained on a diet of noctuid larvae, primarily the tomato moth, L. oleracea. Adult gut preparations were made by removing insects (without starvation) from culture approximately one week after moulting to the adult stage. The insects were chilled for one hour over ice to render them immobile and then dissected in chilled distilled water. The midguts were subsequently transferred to chilled 1.5 $\mathrm{ml}$ microcentrifuge tubes containing $1 \mathrm{mM}$ dithiothrietol (DTT; included as a reducing agent) $(1$ gut $/ 40 \mu \mathrm{l})$. The guts were subsequently homogenised and then centrifuged at $10000 \mathrm{~g} / 4^{\circ} \mathrm{C}$ for $10 \mathrm{~min}$. Following this, the supernatants were extracted with three volumes of chloroform and centrifuged at $1500 \mathrm{~g} / 4^{\circ} \mathrm{C}$ for a further $15 \mathrm{~min}$. The aqueous phase was collected, flash frozen and stored at $-20^{\circ} \mathrm{C}$ until use. Protease extracts from nymph guts were prepared as above (1 gut / $20 \mathrm{ml} 1 \mathrm{mM} \mathrm{DTT})$. The protein contents of all extracts were determined as per Bradford (1976) using bovine serum albumin as a standard.

Salivary glands were obtained by gently pressing down on the thorax of chilled $P$. maculiventris adults and teasing off the prothorax with forceps to reveal the glands. All lobes of the glands were subsequently removed, briefly rinsed in chilled distilled water and then placed in $1.5 \mathrm{ml}$ microcentrifuge tubes held over ice with $1 \mathrm{mM}$ DTT $(1$ gland / $5 \mu \mathrm{l})$. Salivary gland preparations, and protein quantification, were conducted as above.

\section{Proteinase activity using synthetic substrates}

General proteolytic activity was determined using azocasein as substrate at a final concentration of $0.25 \%(\mathrm{w} / \mathrm{v})$ (Walker et al., 1998). To determine the $\mathrm{pH}$ optimum for gut proteolytic activity, an overlapping range of buffers was used (all $100 \mathrm{mM}$ ): citrate-phosphate ( $\mathrm{pH} 3.0-8.0$ ), MES (2-[-morpholino]ethanesulfonic acid) ( $\mathrm{pH} 5.5-6.5)$, bis-Tris propane ( $\mathrm{pH}$ 6.5-9.5) and CAPS (3-[cyclohexylamino]-propanesulfonic acid) (pH 9.5-11.0). Proteinase activity was also determined using the synthetic substrates Z-Phe-Arg- $p$ NA, BA $p$ NA and SAAPF $p$ NA over the $\mathrm{pH}$ range described above at final substrate concentrations of $0.5 \mathrm{mM}$, respectively. For Z-Phe-Arg- $p \mathrm{NA}$ only, to inhibit oxidative processes the buffer was modified to contain $10 \mathrm{mM}$ DTT, $2 \mathrm{mM}$ EDTA and 2\% Brij 35. Proteolytic activity of salivary gland extracts was determined using the fluorescent protein substrate BODIPY-FL casein (EnzChek Protease Assay Kit, Molecular Probes). The optimal $\mathrm{pH}$ for activity was determined using $100 \mathrm{mM}$ citrate-phosphate $(\mathrm{pH} \mathrm{3.0-6.0)}$ and 100 $\mathrm{mM}$ borate ( $\mathrm{pH} 6.0-11.0)$ buffers. Briefly, $5 \mu 1$ of salivary gland extract was added to $185 \mu 1$ of buffer and the reaction initiated by the addition of $10 \mu \mathrm{l}$ of $10 \mathrm{mM}$ substrate (in distilled water; $0.5 \mathrm{mM}$ final concentration). Fluorescence was monitored in a fluorescence microtitre plate reader (excitation / emission maxima 485 / $538 \mathrm{~nm}$ ) at room temperature every $2 \mathrm{~min}$. Incubations were performed in triplicate alongside appropriate controls.

\section{Inhibition studies}

The effect of proteinase inhibitors on gut proteolytic activity was measured for both adults and nymphs with Z-Phe-Arg- $p$ NA and azocasein as substrate. Chemical inhibitors were made up as aqueous solutions (DTT, E-64, leupeptin, pepstatin, TLCK, EDTA), in ethanol (TPCK) or methanol (PMSF) and stored at $-20^{\circ} \mathrm{C}$. Other inhibitors used (SBBI, SKTI, CpTI, CEW, OC-1) were made up as aqueous solutions. Incubations were conducted at the previously established $\mathrm{pH}$ optima, with the inhibitor preincubated with the enzyme at $30^{\circ} \mathrm{C}$ for 15 min prior to addition 
of substrate. Inhibitor concentrations used were chosen to fall within their effective ranges (Beynon \& Bond, 2001) or on the basis of their effects in previously investigated systems (Walker et al., 1998; Down et al., 1999). All incubations were conducted in triplicate alongside appropriate controls. The results are expressed as residual activity relative to the control $(100 \%$ activity).

The inhibition of salivary gland extracts was determined using the procedures described above for general proteolysis. In all assays, volumes of buffer used were adjusted to allow for the addition of inhibitors so as to ensure constant final substrate concentrations.

\section{Effect of feeding status on $\boldsymbol{P}$. maculiventris gut proteolysis}

The effect of the feeding status of $P$. maculiventris adults was determined through feeding adult males (1-2 weeks old) L. oleracea larvae ad libitum for one week and then subsequently removing prey items and maintaining the bugs on water only. The predators were kept individually in $250 \mathrm{ml}$ pots in order to prevent cannibalism and guts were removed at $0,48,72$ and 96 $\mathrm{h}$ after the cessation of feeding and extracts prepared as described above. A minimum of five insects were used for each time point and the rate of proteolysis was determined with Z-Phe-Arg- $p$ NA as substrate. The rates of proteolysis at given time points were compared through calculating the rates per unit protein used in each of the assays followed by calculating the proportion of the mean control rate that each assay proceeded at.

\section{Determination of proteinase activity by gel electrophoresis}

In-gel proteinase activity was conducted according to Sarath et al. (2001). Adult and nymph gut extracts, as well as salivary gland preparations, were run on $12.5 \%$ SDS-PAGE minigels that had been co-polymerized with $0.25 \%$ azocasein. Loading buffer did not contain $\beta$-mercaptoethanol and samples were not boiled prior to loading. For each treatment, $10 \mu \mathrm{g}$ of protein was loaded per lane and gels were run at $4{ }^{\circ} \mathrm{C}$. Gels were washed in $1 \%(\mathrm{v} / \mathrm{v})$ Triton X-100 in water for $30 \mathrm{~min}$ prior to incubating in $100 \mathrm{mM}$ MES, pH 6.0, $1 \mathrm{mM}$ DTT overnight at $37^{\circ} \mathrm{C}$. The gels were subsequently stained with $0.05 \%$ Coomassie blue overnight and then briefly destained to reveal proteolytic activity as clear bands. In-gel inhibition of activity was determined through incubation of gel slices with the inhibitors E-64 and TLCK added at $20 \mu \mathrm{M}$ and $500 \mu \mathrm{M}$, respectively.

\section{RESULTS}

\section{Proteolytic activity within $P$. maculiventris guts}

Proteinases extracted from $P$. maculiventris midguts readily cleaved azocasein and Z-Phe-Arg- $p \mathrm{NA}$, substrates that are sensitive to trypsin-like and cathepsin-like enzymes. Using an overlapping buffer system, the optimal $\mathrm{pH}$ for hydrolysis was determined to lie within the buffering capacity of MES ( $\mathrm{pH}$ 5.5-6.5). Incubation of gut extracts with the protein substrate azocasein gave a broad peak of activity, with hydrolysis $>30 \%$ of the maximum value over the $\mathrm{pH}$ range $4.0-8.0$, with optimal activity falling between $\mathrm{pH} 5.5-6.5$ for both adults and nymphs (Fig. 1). The $\mathrm{pH}$ optima for larval and adult gut proteolytic activity using the synthetic substrate Z-PheArg- $p$ NA gave similar values to those obtained for azocasein (data not shown).

\section{Inhibitor studies}

Inhibitor studies for the four mechanistic classes of proteinases were used to characterise the proteinases present
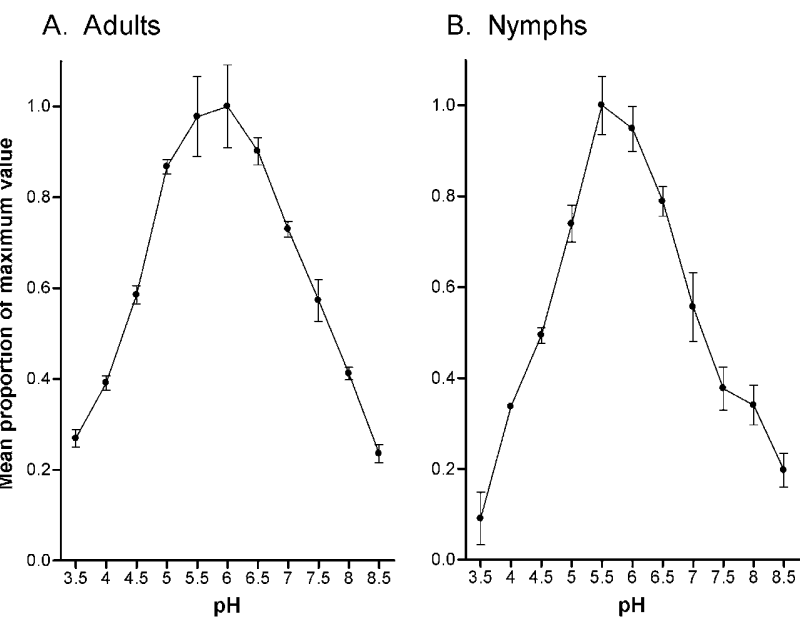

Fig. 1. pH optima for P. maculiventris gut proteolytic activity for (A) adults and (B) nymphs, with azocasein as substrate. Assays were carried out in triplicate.

within the midgut of both the adult and nymphal stages of $P$. maculiventris (Table 1). Using these diagnostic inhibitors with Z-Phe-Arg- $p$ NA and azocasein substrates, the results indicated that cysteine proteinases accounted for almost all of the detectable activity. The three specific cysteine proteinase inhibitors (OC-1, E64, CEW) all showed substantial inhibition of adult gut proteolysis for Z-Phe-Arg- $p$ NA. In adults, OC-1 reduced activity to $4.1 \%$ of that of the controls at an assay concentration of $40 \mu \mathrm{M}$ and to $12.0 \%$ at a concentration of $4.0 \mu \mathrm{M}$, whilst in nymphs this inhibitor (at the lower concentration) reduced proteolysis to ca. $44 \%$ of the control value. In contrast, OC-1 $(40 \mu \mathrm{M})$ appeared to be a more effective inhibitor of gut proteolysis in the nymph, compared to the adult, when azocasein was used as the substrate. Both E-64 and CEW cystatin markedly inhibited the rates of proteolysis in adult and nymph extracts with inhibition of Z-Phe-Arg- $p$ NA hydrolysis being greater than that of azocasein hydrolysis.

The serine/cysteine inhibitor leupeptin was the most effective inhibitor tested, reducing hydrolytic activity to less than $1.3 \%$ and $0.8 \%$ of the control values in adults and nymphs, respectively. Chymostatin, an inhibitor of serine proteinases and some cysteine proteinases, also gave high levels of inhibition, particularly of nymphal gut extracts, where residual activity was reduced to $2.5 \%$ and $9.7 \%$ of the control values for Z-Phe-Arg- $p$ NA and azocasein substrates, respectively. The chemical inhibitor PMSF, diagnostic for serine proteinases within the concentration ranges used, gave only slight inhibition, whilst the plant-derived serine proteinase inhibitors (SKTI, $\mathrm{SBBI}$ and $\mathrm{CpTI}$ ) and the aspartic proteinase inhibitor pepstatin did not inhibit Z-Phe-Arg- $p$ NA or azocasein hydrolysis in either adults or nymphs. In contrast, the chemical inhibitors TPCK and TLCK, which are generally regarded as serine proteinase inhibitors, both gave significant inhibition of Z-Phe-Arg- $p \mathrm{NA}$, particularly the latter which reduced activity to $5.1 \%$ of the controls in adult gut extracts. Pepstatin, an inhibitor of aspartic proteases, for the most part, had no inhibitory activity and, 
TABLE 1. Effects of a range of inhibitors on the residual proteolytic activity of mid-gut extracts from adult and fifth instar nymphs of P. maculiventris.

\begin{tabular}{|c|c|c|c|c|c|c|}
\hline \multirow[b]{2}{*}{ Inhibited class } & \multirow[b]{2}{*}{ Inhibitor } & \multirow[b]{2}{*}{$\begin{array}{l}\text { Final assay } \\
\text { conc. }\end{array}$} & \multicolumn{2}{|c|}{ Adult gut extract } & \multicolumn{2}{|c|}{ Nymph gut extract } \\
\hline & & & $\begin{array}{c}\text { Residual activity (\%) } \\
\text { against Z-Phe-Arg- } p \text { NA }\end{array}$ & $\begin{array}{l}\text { Residual activity (\%) } \\
\text { against azocasein }\end{array}$ & $\begin{array}{c}\text { Residual activity (\%) } \\
\text { against Z-Phe-Arg- } p \text { NA }\end{array}$ & $\begin{array}{c}\text { Residual activity (\%) } \\
\text { against azocasein }\end{array}$ \\
\hline None & & & $100 \%$ & $100 \%$ & $100 \%$ & $100 \%$ \\
\hline \multirow[t]{8}{*}{ Serine } & PMSF & $5 \mathrm{mM}$ & 88.4 & 96.3 & 99.0 & 84.6 \\
\hline & TPCK & $100 \mu \mathrm{M}$ & 69.4 & 30.4 & 19.7 & 37.2 \\
\hline & TLCK & $100 \mu \mathrm{M}$ & 5.1 & 19.7 & 15.2 & 19.1 \\
\hline & Chymostatin & $40 \mu \mathrm{M}$ & 11.0 & 31.8 & 2.5 & 9.7 \\
\hline & & $4 \mu \mathrm{M}$ & 26.1 & 33.7 & 14.8 & 44.1 \\
\hline & SKTI & $1.2 \mu \mathrm{M}$ & 118.9 & 105.1 & 90.5 & 94.9 \\
\hline & SBBI & $2.4 \mu \mathrm{M}$ & 109.8 & 107.7 & 100.0 & 93.4 \\
\hline & CpTI & $1.2 \mu \mathrm{M}$ & 128.1 & 99.8 & 98.1 & 101.9 \\
\hline \multirow[t]{4}{*}{ Cysteine } & E-64 & $4 \mu \mathrm{M}$ & 5.8 & 19.9 & 1.9 & 2.5 \\
\hline & CEW cystatin & $2 \mu \mathrm{M}$ & 16.3 & 28.8 & 19.8 & 35.4 \\
\hline & OC-1 & $40 \mu \mathrm{M}$ & 4.1 & 23.7 & 28.4 & 2.4 \\
\hline & & $4 \mu \mathrm{M}$ & 12.0 & 50.6 & 44.4 & 67.7 \\
\hline Aspartic & Pepstatin & $1 \mu \mathrm{M}$ & 122.3 & 102.5 & 165.2 & 92.5 \\
\hline Metallo & EDTA & $40 \mu \mathrm{M}$ & 115.0 & 108.3 & 153.4 & 94.1 \\
\hline Serine/cysteine & Leupeptin & $100 \mu \mathrm{M}$ & 1.34 & 23.2 & 0.8 & 24.7 \\
\hline
\end{tabular}

conversely, proteolytic activity was higher than in the control assays, particularly those using Z-Phe-Arg- $p$ NA.

\section{Effect of starvation on endogenous proteolytic activity}

The effect of starvation on endogenous proteolytic activity present in the adult gut is shown in Fig. 2. Proteolytic activity showed a marked decline over the course of $96 \mathrm{~h}$ of starvation. After $48 \mathrm{~h}$ of starvation, proteolytic activity was similar to that in the non-starved insects, at approximately $90 \%$ of the value for recently fed insects. After this time, however, values fell to approximately $65 \%$ at $72 \mathrm{~h}$ and $11 \%$ at $96 \mathrm{~h}$ after the start of starvation.

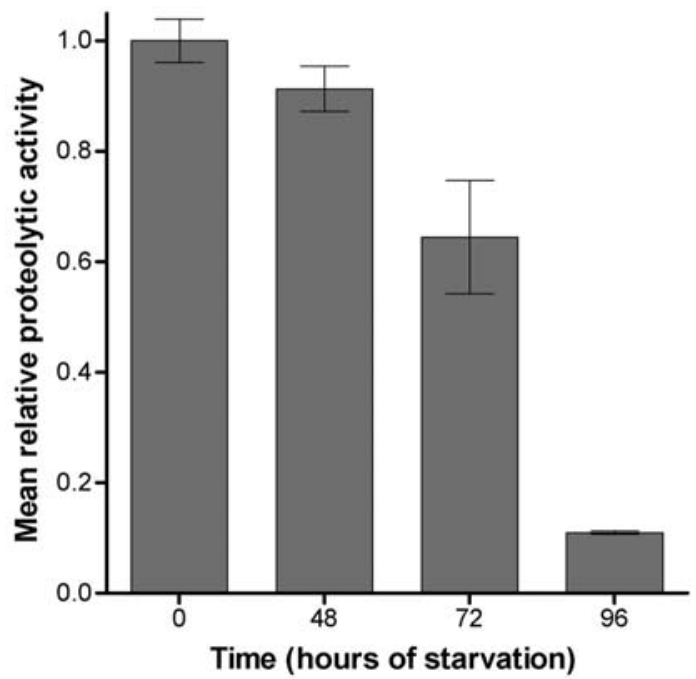

Fig. 2. Effect of starvation on the relative proteolytic activity present in the guts of adult $P$. maculiventris. Values show the rates of the hydrolysis of Z-Phe-Arg- $p \mathrm{NA}$ as a proportion of the values obtained from non-starved insects. Assays were carried out in triplicate.

\section{In-gel proteinase assays}

Four clear bands, representing proteolytic activity, were observed when gut extracts were separated on azocasein/SDS-PAGE gels and incubated in the absence of inhibitors (Fig. 3). However, one of the bands (P2) was generated by two incompletely resolved enzymes that only appeared as discrete bands in the presence of E64 for both adult and nymphal gut extracts. The bands of activity that were apparent in uninhibited gels corresponded to molecular weights of approximately $30 \mathrm{kDa}$, $36 \mathrm{kDa} 50 \mathrm{kDa}$ and a larger band in the region of 110
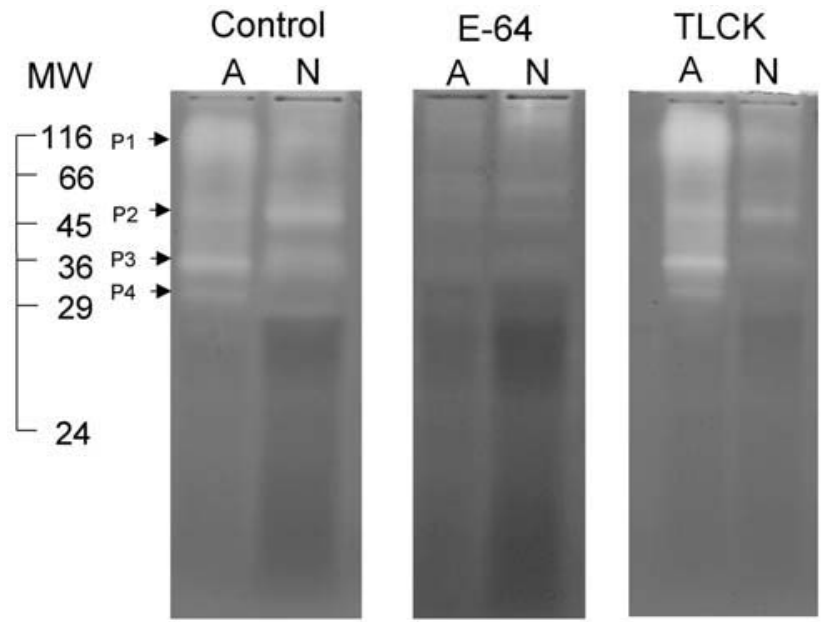

Fig. 3. The presence of proteolytic activity within the extract of $P$. maculiventris adult (lane 1) and nymph (lane 2) gut extracts denoted by clear regions in the gel where incorporated azocasein has been hydrolysed. Lanes 3 and 4 show hydrolysis by extracts when incubated in the presence of $20 \mu \mathrm{M} \mathrm{E}-64$ and lanes 5 and 6 in the presence of $500 \mu \mathrm{M}$ TLCK. 


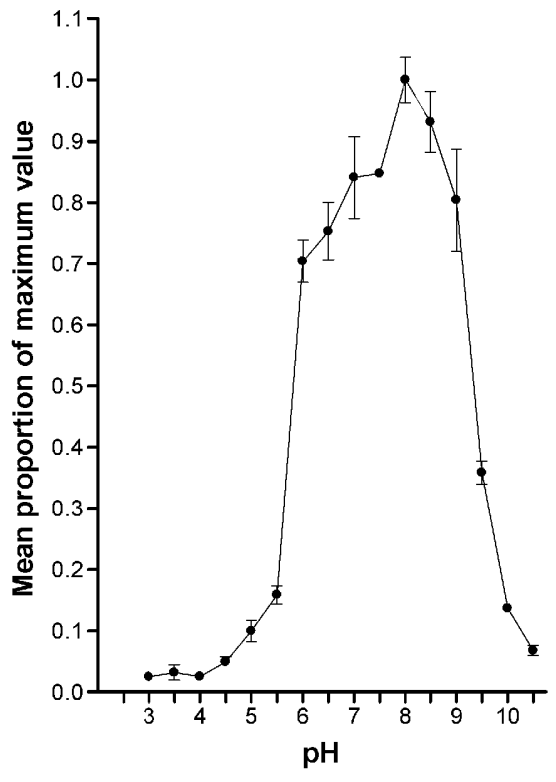

Fig. 4. Effect of $\mathrm{pH}$ on the hydrolysis of BODIPY-FL casein by salivary gland extracts from of $P$. maculiventris adults.

kDa. Proteolysis bands produced by nymphal and adult extracts were similar to one another, although the $\mathrm{P} 4$ proteinase in the nymphal extracts migrated further than the equivalent enzyme(s) from adults which may indicate a different form of this enzyme in nymphs. The intensities of the bands P1 and P2 (control gels) indicated that quantitative differences in the different proteinases may be present between adult and nymphal bugs.

Incubation of gel slices in $20 \mu \mathrm{M}$ E-64 inhibited most caseinolytic activity present in adult gut extracts, and resulted in markedly reduced activity in the nymphal enzymes. Incubation in $500 \mu \mathrm{M}$ TLCK, however, gave little inhibition of proteases in the adult gut although the nymphal extracts showed reduced activity, particularly in bands $\mathrm{P} 3$ and $\mathrm{P} 4$.

TABLE 2. Effect of a range of inhibitors against adult salivary gland extracts of $P$. maculiventris. Proteinase activity was measured using BODIPY-FL casein as substrate at $\mathrm{pH}$ 8.0.

\begin{tabular}{ccrc}
\hline Inhibitor class & Inhibitor & $\begin{array}{c}\text { Final assay } \\
\text { conc. }\end{array}$ & $\begin{array}{c}\text { Residual } \\
\text { activity (\%) }\end{array}$ \\
\hline None & & & 100.0 \\
Serine & PMSF & $5 \mathrm{mM}$ & 53.14 \\
& TPCK & $100 \mu \mathrm{M}$ & 112.0 \\
& TLCK & $100 \mu \mathrm{M}$ & 83.4 \\
& Chymostatin & $100 \mu \mathrm{M}$ & 99.4 \\
& SKTI & $1.2 \mu \mathrm{M}$ & 114.7 \\
& SBBI & $2.4 \mu \mathrm{M}$ & 83.0 \\
Cysteine & CpTI & $1.2 \mu \mathrm{M}$ & 100.0 \\
& E-64 & $4 \mu \mathrm{M}$ & 93.9 \\
& CEW cystatin & $2 \mu \mathrm{M}$ & 84.6 \\
Aspartic & OC-1 & $40 \mu \mathrm{M}$ & 108.2 \\
Metallo & Pepstatin & $1 \mu \mathrm{M}$ & 90.8 \\
Serine/cysteine & EDTA & $40 \mu \mathrm{M}$ & 86.4 \\
& Leupeptin & $100 \mu \mathrm{M}$ & 57.8 \\
\hline
\end{tabular}

\section{Inhibition of salivary gland extracts}

The $\mathrm{pH}$ optimum for proteolytic activity in the salivary glands of $P$. maculiventris was determined over a $\mathrm{pH}$ range of 3.0-11.0 (citrate-phosphate buffer: $\mathrm{pH} 3.0-6.0$; borate buffer $\mathrm{pH}$ 6.0-11.0). A moderately narrow $\mathrm{pH}$ range of activity was obtained when BODIPY-FL casein was used as the substrate, with maximal activity at $\mathrm{pH}$ 8.0 ; activity remained $>70 \%$ of the maximal activity down to $\mathrm{pH}$ 6.0, below which it rapidly declined (Fig. 4). The $\mathrm{pH}$ optima of the salivary gland proteinases corresponded well to the $\mathrm{pH}$ of the haemolymph of $L$. oleracea prey, which was determined to be ca. pH 7.8 using narrow range indicator paper (data not shown).

Little inhibition of the activity of the saliva was obtained using a range of inhibitors (Table 2). However, the serine proteinase inhibitor PMSF gave the most marked reduction in the rate of proteolysis, with a residual activity of approximately $53 \%$. With the exception of SBBI, the plant-derived serine proteinase inhibitors (CpTI and SKTI) gave no inhibition at the concentrations used. Leupeptin, an inhibitor of both serine and cysteine proteinases was the only other inhibitor to reduce residual activity to below $60 \%$ of the controls.

\section{DISCUSSION}

Studies using diagnostic inhibitors indicate that the primary gut enzymes responsible for protein digestion in $P$. maculiventris are of the cysteine mechanistic class. This finding is in accordance with previous work that has demonstrated that cysteine proteinases are the predominant midgut digestive enzymes in the Hemiptera (Terra \& Ferriera, 1994). Little hydrolysis of BA $p \mathrm{NA}$, a substrate for trypsin-like enzymes, was observed and, when coupled with the insensitivity of the proteinase to $\mathrm{CpTI}$, it appears that little tryptic activity is present in the midgut of this insect. This corroborates the findings of Stamopoulos et al. (1993) who reported only trace trypsin/chymotrypsin activity in the gut of $P$. maculiventris.

In-gel assays showed that at least four different proteolysis bands were present, although the partially denaturing methodology of the electrophoresis does not preclude the presence of further proteolytic enzymes that were not detected. The poor resolving power of the gel system obscured a further band which only became apparent when the gel was incubated in the presence of inhibitors, thus one band (P2) was shown to be comprised of two distinct proteinases. Bands of activity were very similar for both adults and nymphs which probably reflects the similarity of the nymphal diet with that of the adult predator. Inhibition of all bands was achieved when gel slices were incubated with the cysteine proteinase inhibitor E-64, whilst no inhibition of adult proteinases by TLCK was observed, although the nymphal proteinases showed some sensitivity to this inhibitor. Not all bands produced by nymphal proteinases were inhibited to the same extent by E-64 and TLCK, indicating differential sensitivity of the different enzymes to inhibition. Interestingly, Bouchard et al. (2003b) showed a pattern of five proteolysis bands in a gelatin / SDS-PAGE system 
for proteinases of the predatory stinkbug $P$. bioculatus, and demonstrated that the proteinases present exhibited differential sensitivities to OC-1. Proteolytic activity declined markedly in starved $P$. maculiventris. Although measures were taken to ensure all insects had access to prey prior to dissection, potential qualitative and quantitative differences in the in-gel proteinase activity may have been due to differences in the feeding status of insects used in these assays.

The alkaline $\mathrm{pH}$ optima, and sensitivity to serine proteinase inhibitors, indicate that the salivary proteinases of $P$. maculiventris are predominantly of the serine mechanistic class, as has been previously reported for a number of hemipteran species (Cohen, 1993; Terra \& Ferriera, 1994). However, moderate levels of inhibition by a number of the cysteine proteinase inhibitors tested in the present study indicate that cysteine proteinases may also be present, as was indicated by Zeng et al. (2002) in the hemipteran Lygus hesperus Knight. Despite the lack of any suppression of salivary proteinases by the trypsin inhibitors used, the sequencing of cDNA clones made from the salivary glands of $P$. maculiventris has revealed the presence of a trypsin-like precursor (Bell, 2002). A search of the GenBank database showed that the deduced amino acid sequence of this trypsin-like protein was most similar to a sequence for a trypsin-like precursor derived from the hemipteran L. hesperus (Zeng et al., 2002). Thus, the evidence suggests that trypsin is a component of the saliva of $P$. maculiventris. The slight inhibition (ca. $14 \%$ ) of salivary proteolytic activity by the metalloproteinase inhibitor EDTA provided only weak evidence for the presence of carboxypeptidases in the salivary gland extracts. However, carboxypeptidase-like cDNAs have also been isolated from the salivary glands of this insect (Bell, 2002) and it is likely that carboxypeptidase activity is present within the saliva of Podisus maculiventris.

The findings of this investigation indicate that $P$. maculiventris utilises several cysteine proteinases for gut proteolysis that are sensitive to inhibitors of this mechanistic class. As a result, whilst the enzymes are insensitive to plant-derived serine proteinase inhibitors, such as CpTI and SKTI, the cysteine proteinase inhibitor OC-1 markedly reduces proteolysis. This finding would suggest that exposure to $\mathrm{OC}-1$ via prey that had ingested plant material expressing this inhibitor has the potential to cause adverse effects in $P$. maculiventris. However, previous studies investigating the effects of PIs on predatory insects show that whilst enzyme activity is frequently inhibited in vitro by OC-1, prey-mediated effects at the third trophic level are often not observed. This may be explained by the upregulation of insensitive proteinases in response to exposure to the PI that may serve to negate any impact on the beneficial insects in question (Bouchard et al., 2003b; Ferry et al., 2003). It is therefore possible that $P$. maculiventris will respond in a similar way to exposure to OC-1, although this remains to be demonstrated. Despite the fact that Bell et al. (2004) reported some detrimental effects on the biology of this predator when exposed to $\mathrm{CpTI}$, the predominance of cysteine digestive proteinases within the gut of $P$. maculiventris indicate that the ingestion of serine proteinase inhibitors via prey is unlikely to have any direct impact on its gut digestive proteolytic activity. The results of inhibitor studies with salivary gland extracts of $P$. maculiventris, however, indicate that the efficiency of pre-oral digestion may be, in part, suppressed by the accumulation of serine proteinase inhibitors within prey insects. Preoral digestion is an important component of food utilization in a number of predaceous insects, including $P$. maculiventris (see Cohen, 1995). Due to the large investment that a predator makes through the injection of a range of hydrolytic enzymes into a prey item, loss of preoral proteolytic efficiency may have adverse effects on a given predator. The saliva of $P$. maculiventris is clearly complex, and comprised of a range of digestive enzymes, which may indicate that the likelihood of adverse effects through prey-mediated exposure to a single proteinase inhibitor is probably slight.

The fact that, of the plant-derived inhibitors investigated, OC-1 had the greatest impact on the proteolytic activity of the predator would suggest that there may be some risk attached to the deployment of transgenic crops expressing cysteine proteinase inhibitors. This is particularly pertinent when one considers that intact transgene proteins, including PIs, have been shown to accumulate within the bodies of a number of phytophagous pest species (Down et al., 1999; Ferry et al., 2003) and therefore have the potential to be consumed in appreciable quantities by predatory insects. Due to the importance of $P$. maculiventris, and the increasingly widespread interest in expressing cystatins such as OC-1 in transgenic crop plants, it is strongly indicated that further studies should be undertaken to assess the potential effects of this insecticidal protein on $P$. maculiventris, both in terms of its developmental biology and its physiological processes.

\section{REFERENCES}

Ashouri A., Overney S., Michaud D. \& Cloutier C. 1998: Fitness and feeding are affected in the two spotted stinkbug, Perillus bioculatus, by the cysteine proteinase inhibitor, oryzacystatin I. Arch. Insect Biochem. Physiol. 38: 74-83.

Bell H.A., Fitches E.C., Down R.E., Ford L., Marris G.C., Edwards J.P., Gatehouse J.A. \& Gatehouse A.M.R 2001: Effect of dietary cowpea trypsin inhibitor (CpTI) on the growth and development of the tomato moth Lacanobia oleracea (Lepidoptera: Noctuidae) and on the success of the gregarious ectoparasitoid Eulophus pennicornis (Hymenoptera: Eulophidae). Pest Manag. Sci. 57: 57-65.

BeLl H.A. 2002: Tritrophic Interactions between a Pest Noctuid, Beneficial Biological Control Agents and Genetically Modified Crops Expressing Anti-Insect Genes. PhD Thesis, University of Newcastle upon Tyne.

Bell H.A., Down R.E., Fitches E.C., Edwards J.P. \& GateHOUSE A.M.R 2004: Impact of genetically modified potato expressing plant-derived insecticidal proteins/insect resistance genes on the predatory bug Podisus maculiventris (Say). Biocontrol Sci. Techn. 13: 729-741.

Beynon R. \& Bond J.S. 2001: Proteolytic Enzymes: A Practical Approach. Oxford University Press, Oxford, UK, 340 pp. 
Bouchard E., Michaud D. \& Cloutier C. 2003a: Molecular interactions between an insect predator and its herbivore prey on transgenic potato expressing a cysteine proteinase inhibitor from rice. Mol. Ecol. 12: 2429-2437.

Bouchard E., Cloutier C. \& Michaud D. 2003b: Oryzacystatin I expressed in transgenic potato induces digestive compensation in an insect natural predator via its herbivorous prey feeding on the plant. Mol. Ecol. 12: 2439-2446.

BRADFORD M. 1976: A rapid and sensitive method for the quantification of microgram quantities of protein using the principle of dye-binding. Anal. Biochem. 72: 548-254.

Burgess E.P.J., Lovei G.L., Malone L.A., Nielson I.W, Gatehouse H.S. \& Christeller J.T. 2002: Prey-mediated effects of the protease inhibitor aprotinin on the predatory carabid beetle Nebria brevicollis. J. Insect Physiol. 48: 1093-1101.

Burrow P.R., Barker A.D.P., Newell C.A. \& Hamilton W.D.O. 1998: Plant derived enzyme inhibitors and lectins for resistance against plant parasitic nematodes in transgenic crops. Pestic. Sci. 52: 176-183.

CoHen A.C. 1993: Organization of digestion and preliminary characterization of salivary trypsin-like enzymes in the predaceous heteropteran, Zelus renardii. J. Insect Physiol. 39: 823-829.

CoHen A.C. 1995: Extra-oral digestion in predaceous terrestrial arthropoda. Annu. Rev. Entomol. 40: 85-103.

Cowgill S.E., Wright C. \& AtKinson H.J. 2002: Transgenic potatoes with enhanced levels of nematode resistance do not have altered susceptibility to non-target aphids. Mol. Ecol. 4: $821-827$.

De Clerce P. 2000: Predaceous stinkbugs (Pentatomidae:Asopinae). In Schaefer C.W \& Panizzi A.R. (eds): Heteroptera of Economic Importance. CRC Press, Boca Raton, pp. 737-789.

Down R.E., Ford L., Mosson H.J., Fitches E., Gatehouse J.A. \& Gatehouse A.M.R. 1999: Protease activity in the larval stage of the parasitoid wasp Eulophus pennicornis (Nees) (Hymenoptera: Eulophidae); effects of protease inhibitors. Parasitology 119: 157-166.

Edmonds H.S., Gatehouse L.N., Hilder V.A. \& Gatehouse J.A. 1996: Inhibitory effects of the cysteine protease inhibitor, oryzacystatin, on digestive proteases and on larval survival and development of the southern corn rootworm (Diabrotica undecimpunctata howardi). Entomol. Exp. Appl. 78: 83-94.

Ferry N., Raemaekers R.J.M., Majerus M.E.N., Jouanin L., Port G., Gatehouse J.A. \& Gatehouse A.M.R. 2003: Impact of oilseed rape expressing the insecticidal cysteine protease inhibitor oryzacystatin on the beneficial predator Harmonia axyridis (multicoloured Asian ladybeetle). Mol. Ecol. 12: 493-504.

Gatehouse J.A. \& Gatehouse A.M.R. 1999: Genetic engineering of plants for insect resistance. In Rechcigl J.E. \& Rechcigl N.A. (eds): Biological and Biotechnological Control of Insect Pests. CRC Press, Boca Raton, pp. 211-241.

Gatehouse A.M.R., Gatehouse J.A. \& Boulter D. 1980: Isolation and characterisation of trypsin inhibitors from cowpea. Phytochemistry 19: 751-755.

Gatehouse A.M.R, Davison G.M., Newell C.A., Merryweather A., Hamilton W.D.O., Burgess E.P.J., Gilbert R.J.C. \& GAtehouse J.A. 1997: Transgenic potatoes with enhanced resistance to the tomato moth, Lacanobia oleracea: Growth room trials. Molec. Breeding 3: 49-63.

Gatehouse A.M.R., Norton E., Davison G.M., BabBe S.M., Newell C.A. \& Gatehouse J.A. 1999: Digestive proteolytic activity in larvae of the tomato moth, Lacanobia oleracea: effects of plant protease inhibitors in vitro and in vivo. $J$. Insect Physiol. 45: 545-558.
Graham J., McNicol R.J. \& Grieg K. 1995: Towards genetic based resistance in strawberry using cowpea trypsin inhibitor gene. Ann. Appl. Biol. 27: 163-173.

Hilder V.A., Gatehouse A.M.R., Sheerman S.E., Baker R.F. \& Boulter D. 1987: A novel mechanism of insect resistance engineered into tobacco. Nature 300: 160-163.

Jongsma M.A. \& Bolter C. 1997: The adaptation of insects to plant protease inhibitors. J. Insect Physiol. 43: 885-895.

Johnston K.A., Gatehouse J.A. \& Anstee J.H. 1993: Effects of soybean protease inhibitors on the growth and development of larval Helicoverpa armigera. J. Insect Physiol. 39: 657-664.

Jounanin L., Bonade-Bottino M., Girard C., Morrot G. \& GiBAND M. 1998: Transgenic plants for insect resistance. Plant Sci. 131: 1-11.

LASKOWSKI M. JR. \& KATO I. 1980: Protein inhibitors of proteinases. Annu. Rev. Biochem. 49: 593-626.

Leple J.C., Bonade-Bottino M., Augustin S., Pilate G., Letan V.D., Delplanque A., Cornu D. \& Jouanin L. 1995: Toxicity to Chrysomela tremulae (Coleoptera: Chrysomelidae) of transgenic poplars expressing a cysteine protease inhibitor. Mol. Breeding 1: 319-328.

Overney S., Yelle S. \& Cloutier C. 1998: Occurrence of cysteine digestive proteases in Perillus bioculatus, a natural predator of the Colorado potato beetle. Comp. Biochem. Physiol. (B) 120: 191-195.

Picard-Nizou A.L., Grison R., Olsen L., Pioche C., Arnold G. \& Pham-Delegue M.H. 1997: Impact of proteins used in plant genetic engineering: Toxicity and behavioural study in the honeybee. J. Econ. Entomol. 90: 1710-1716.

Rahbe Y., Deraison C., Bonade-Bottino M., Girard C., NARdon C. \& Jouanin L. 2003: Effects of the cysteine protease inhibitor oryzacystatin (OC-1) on different aphids and reduced performance of Myzus persicae on OC-1 expressing transgenic oilseed rape. Plant Sci. 164: 441-450.

RYAN C.A. 1990: Protease inhibitors in plants: Genes for improving defences against insects and pathogens. Annu. Rev. Phytopathol. 28: 425-429.

Sane V.A., Nath P. \& Sane P.V. 1997: Development of insectresistant transgenic plants using plant genes: Expression of cowpea trypsin inhibitor in transgenic tobacco plants. Curr. Sci. India 72: 741-747.

Sarath G., Zeece M.G. \& Penheiter A.R. 2001: Protease assay methods. In Beynon R. \& Bond J.S. (eds): Proteolytic Enzymes. 2nd ed. Oxford University Press, Oxford, $340 \mathrm{pp}$.

Stamopoulos D.C., Diamantidis G. \& Chloridis A. 1993: Activités enzymatiques du tube digestif du prédateur Podisus maculiventris (Hem.: Pentatomidae). Entomophaga 38: 493-499.

Terra W.R. \& Ferreira C. 1994: Insect digestive enzymes: properties, compartmentalization and function. Comp. Biochem. Physiol. (B) 109: 1-62.

Walker A.J., Ford L., Majerus M.E.N., Geoghegan I.E., Birch N., Gatehouse J.A. \& Gatehouse A.M.R. 1998: Characterisation of the mid-gut digestive proteinase activity of the twospot ladybird (Adalia bipunctata L.) and its sensitivity to proteinase inhibitors. Insect Biochem. Mol. Biol. 28: 173-180.

Xu D., Xue Q., McElroy D., Mawal Y., Hilder V.A. \& Wu R. 1996: Constitutive expression of a cowpea trypsin inhibitor gene, $\mathrm{CpTI}$ in transgenic rice confers resistance to two major rice insect pests. Mol. Breeding 2: 167-173.

Zeng F., Zhu Y.C. \& Cohen A.C. 2002: Molecular cloning and partial characterization of a trypsin-like protein in salivary glands of Lygus hesperus (Hemiptera: Miridae). Insect Biochem. Mol. Biol. 32: 455-464.

Received November 2, 2004; revised and accepted February 7, 2005 